\title{
A Circularity Assessment for Silicon Solar Panels Based on Dynamic Material Flow Analysis
}

$48^{\text {th }}$ IEEE Photovoltaics Specialists Conference (PVSC 48)

$$
\text { June 21, } 2021
$$

\section{Sherif A. Khalifa $^{1}$}

Benjamin V. Mastrorocco ${ }^{1}$

Dylan D. Au ${ }^{1}$

Teresa M. Barnes ${ }^{2}$

Alberta C. Carpenter ${ }^{2}$

Jason B. Baxter ${ }^{1}$

${ }^{1}$ Department of Chemical and Biological Engineering, Drexel University, Philadelphia 19104, USA.

${ }^{2}$ National Renewable Energy Laboratory, Golden 80401, USA.

\section{GNREL}
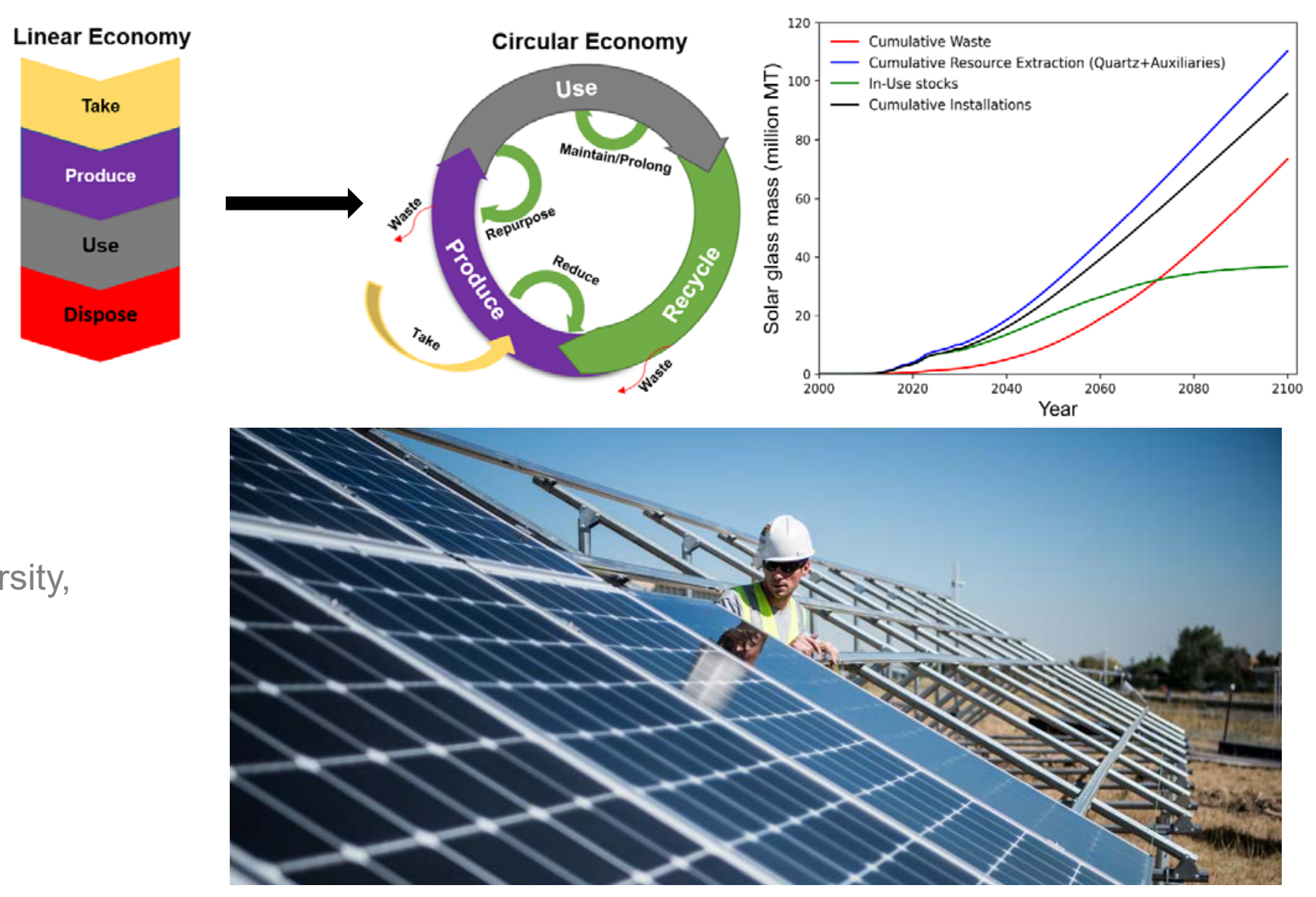


\section{Rapid Deployment of Solar PV is a Key to Faster Decarbonization of Electricity Sector}

U.S. has pledged net-zero carbon emissions by 2050 and $95 \%$ decarbonization of electricity sector by 2035

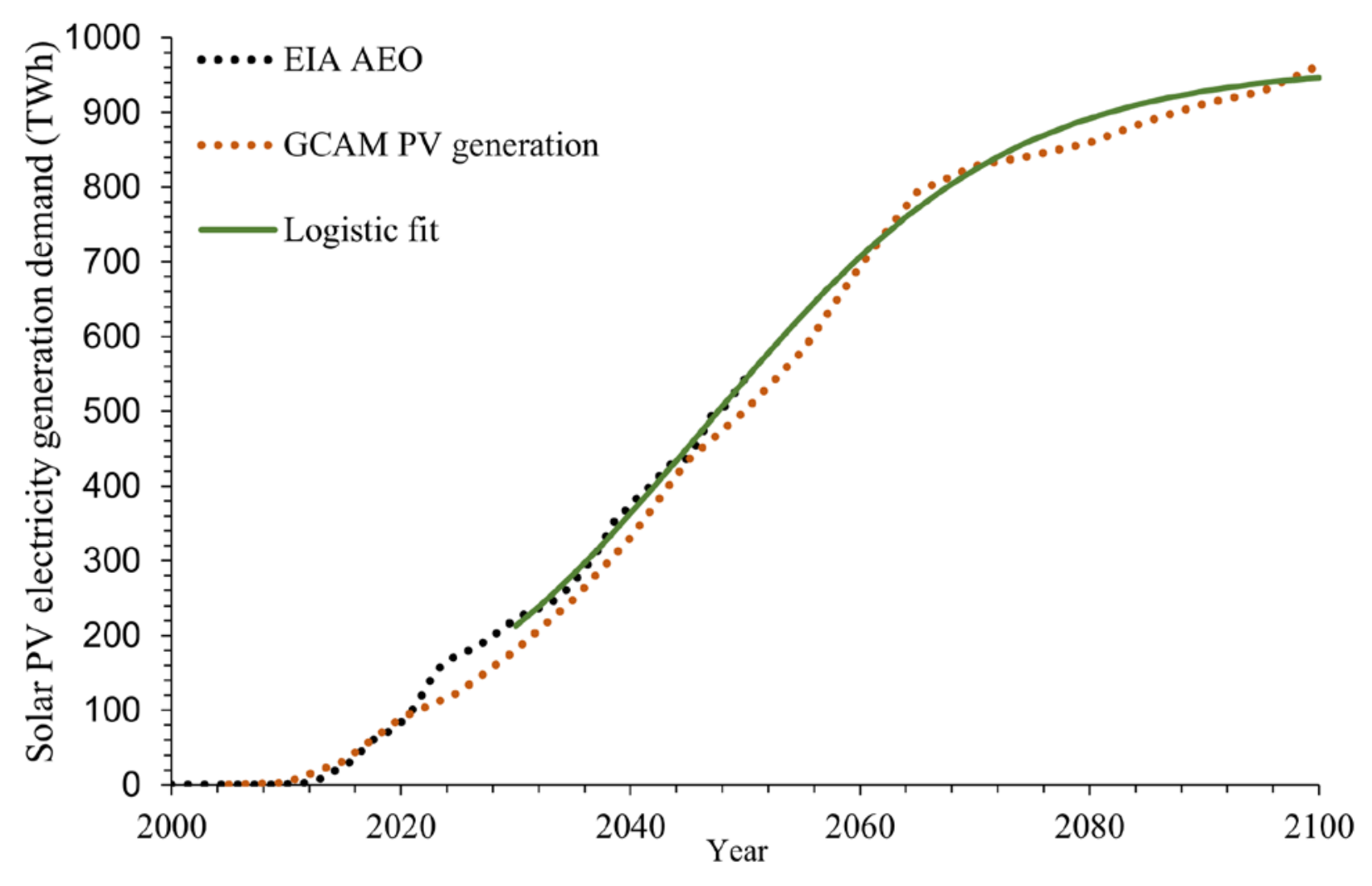

Solar PV share in U.S. electricity generation

How much material is needed? What are the impacts on existing material supply chains due to this rapid growth? 
Fast Growth Now, More Waste Later: A Transition to a Circular Economy is Needed

Initial estimates of End-of-Life (EOL) PV module waste by 2050:

Worldwide $\sim 78$ million metric tons (MT) $\rightarrow \sim 10 \%$ of electronic waste

U.S. $\quad \sim 13$ million MT

Composition by weight

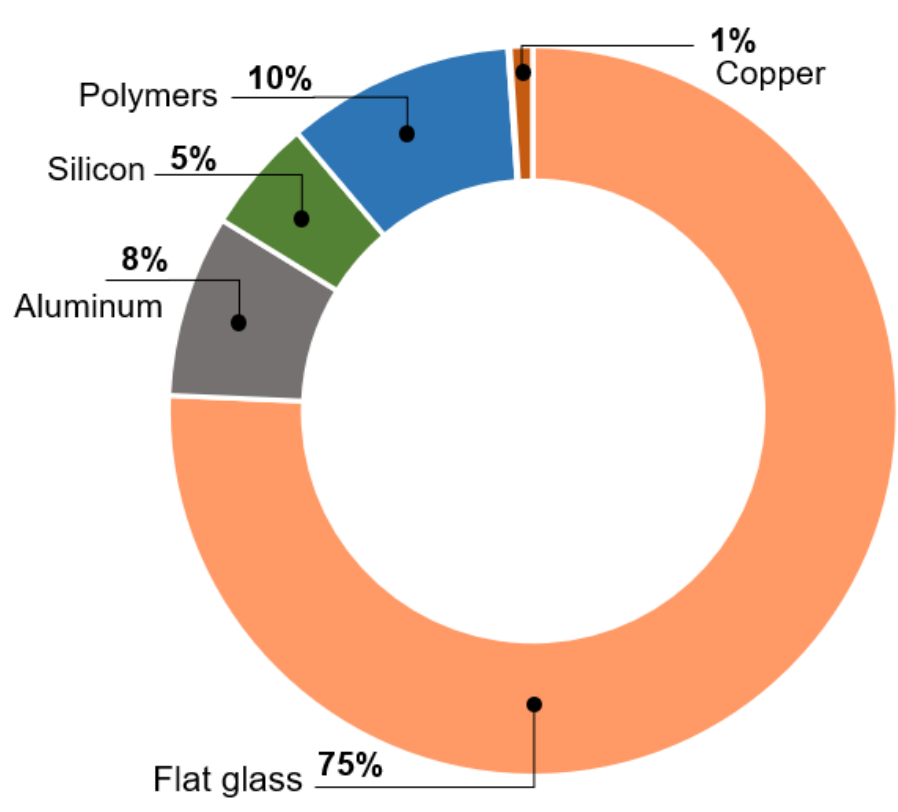

Composition by value

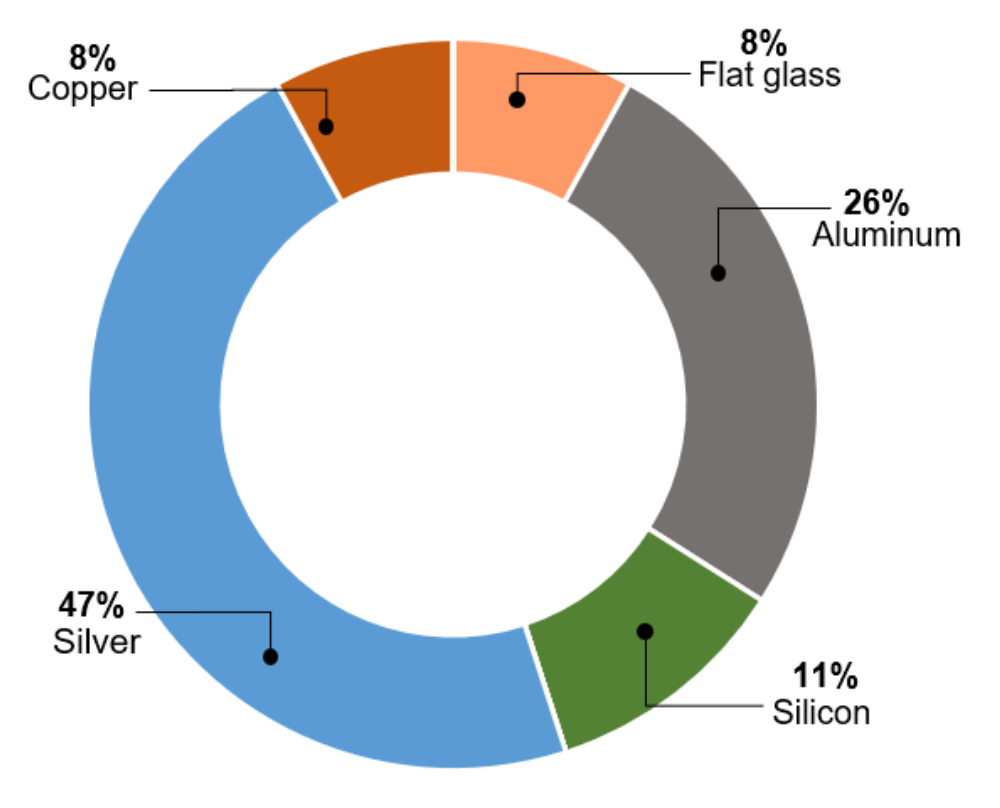

Material flows also carry:

- Energy investments

- Emissions (air, water and soil)

- Environmental impacts

- Economic value $(\$)$

PV glass and aluminum frames are studied here 
Circular Economy Practices Eliminate Waste and Conserve Raw Materials, Thus Promoting Environmental Sustainability

Linear Economy

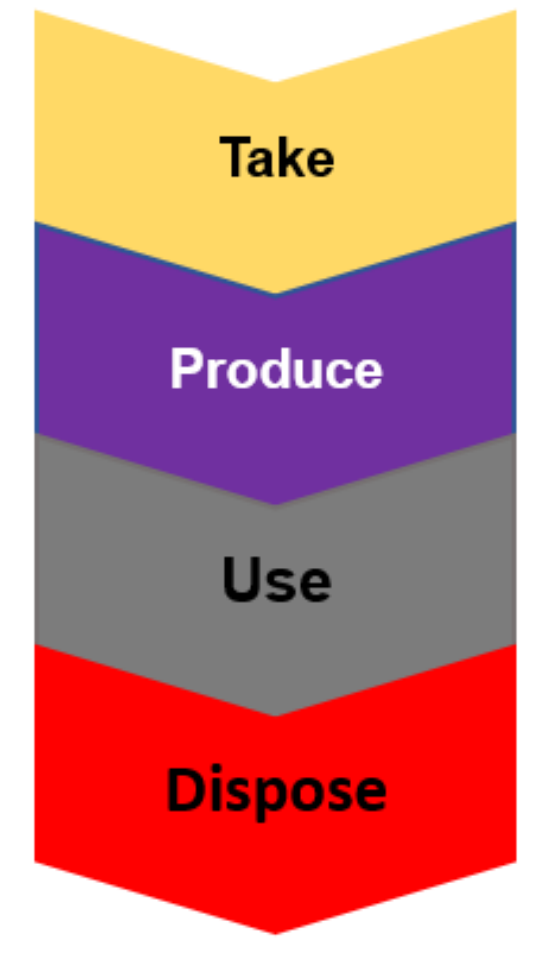

Circular Economy

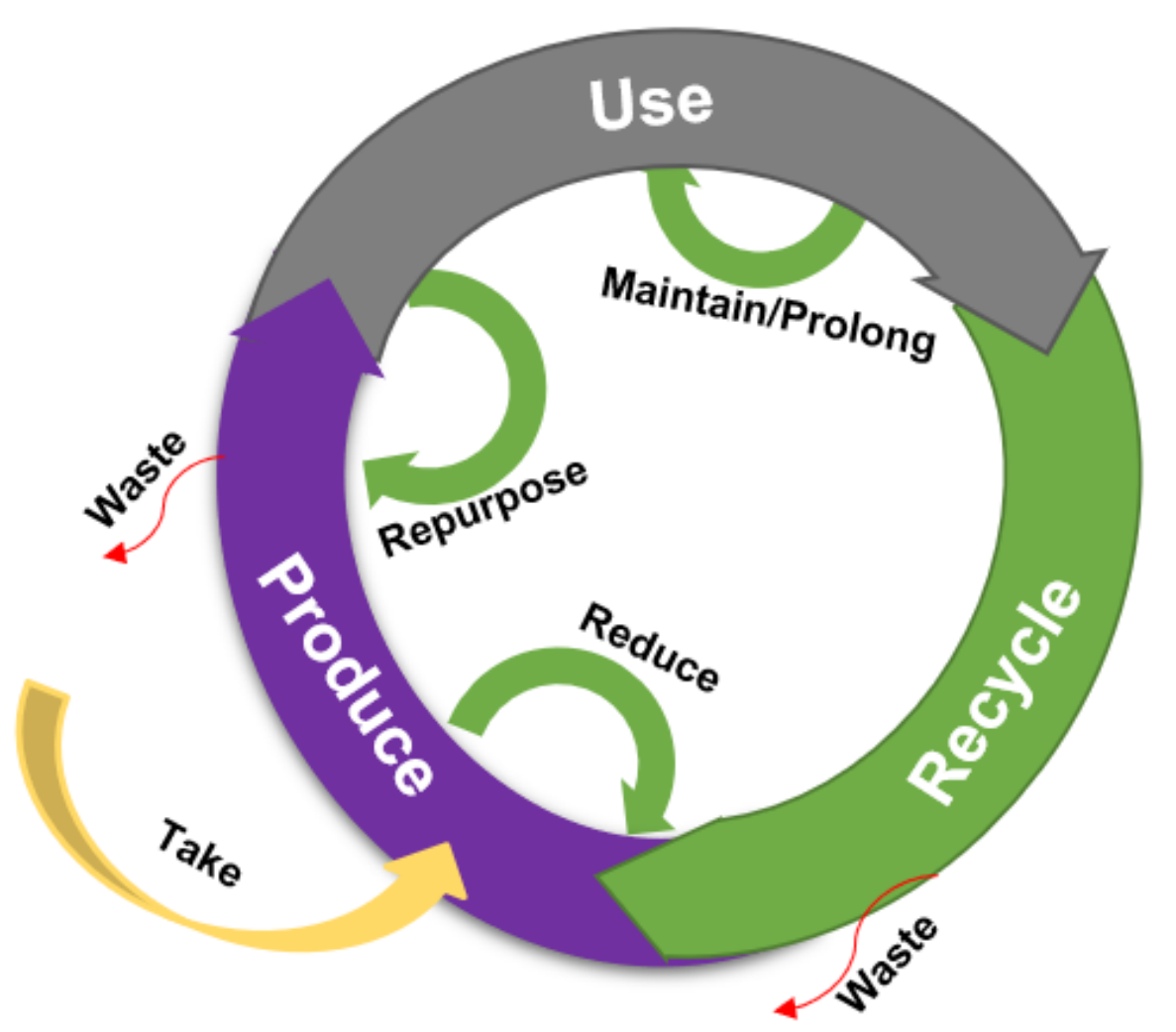

Need to consider material life cycles to quantify impacts of circularity practices 


\section{Photovoltaic Dynamic Material Flow Analysis (PV DMFA) Model}

Open-source, process-based sustainability framework to quantify stocks and flows in the life cycle of PV materials based on historical and predicted utility-scale PV electricity generation in the United States in the period 2000-2100

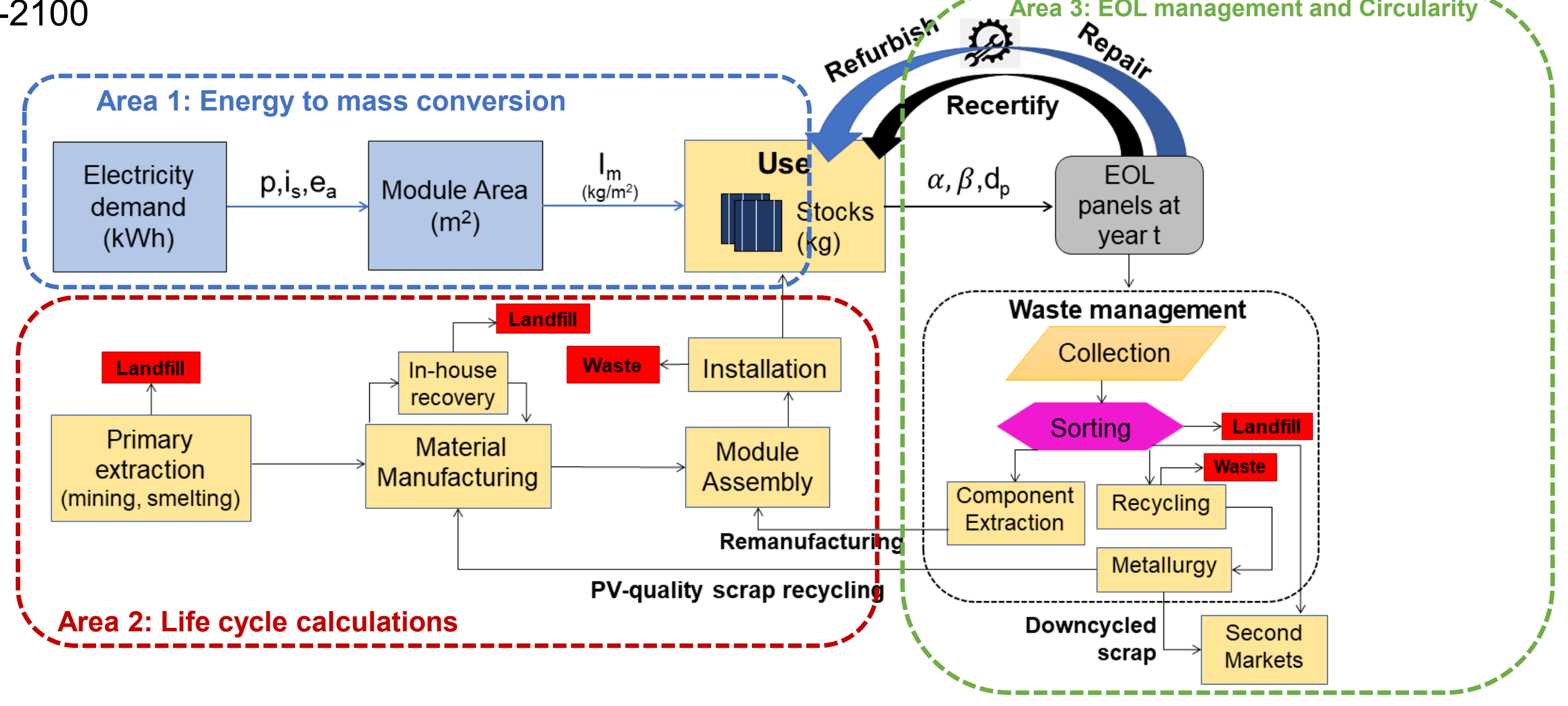




\section{Energy, Area and Mass Cohorts Capture Evolution of Model Parameters with Time}

A cohort is the group of PV panels installed in a given year with a unique set of parameters

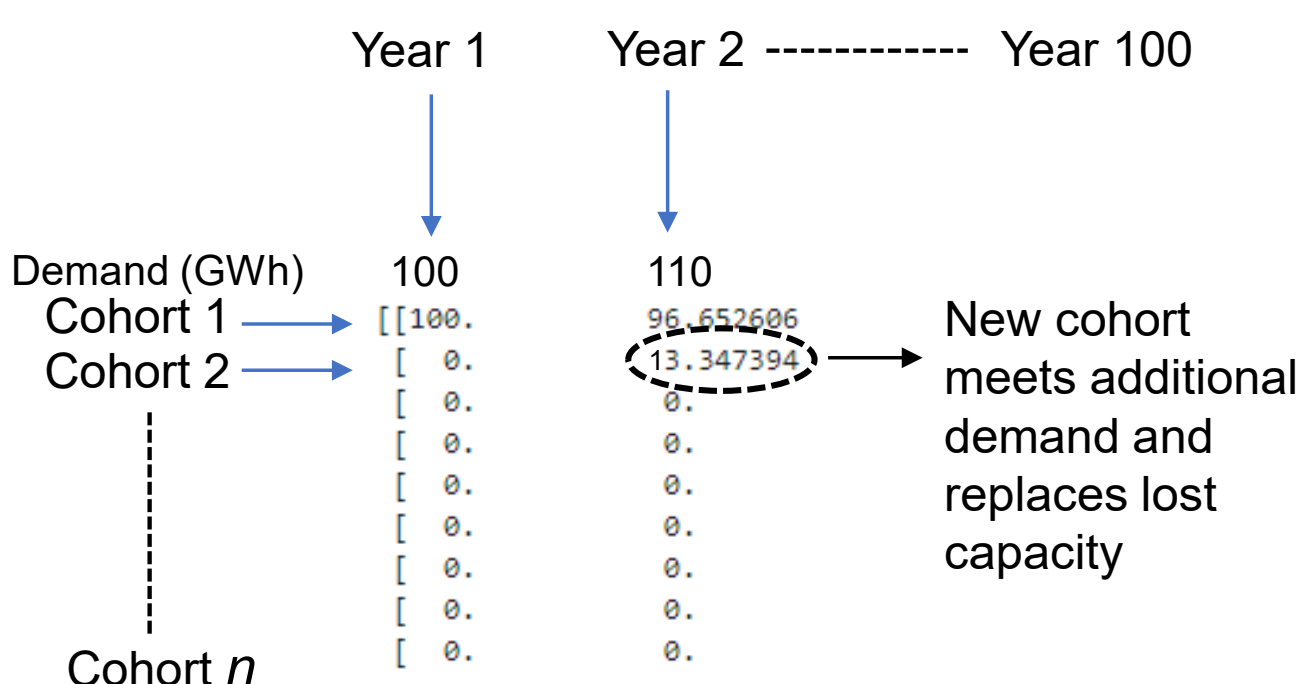

Hvpothetical example of enerqv cohort calculation

Energy

cohorts

\section{Module Area} cohorts $\left(\mathrm{m}^{2}\right)$
Use

Material

stocks
- U.S. utility-scale PV demand predictions are sourced from EIA and GCAM

- Cohort electricity generation capacity decreases due to panel efficiency degradation AND random losses throughout system lifetime modelled by 2-parameter Weibull lifetime probability distribution

- A cohort reaches EOL if cumulative Weibull is $98 \%$ OR if efficiency degradation is $80 \%$ of installation efficiency ( 20\% degradation)

Energy cohorts are used to estimate module area cohorts that are converted into material installations, in-use stocks and retirements 


\section{Energy, Area and Mass Cohorts Capture Evolution of Model Parameters with Time}

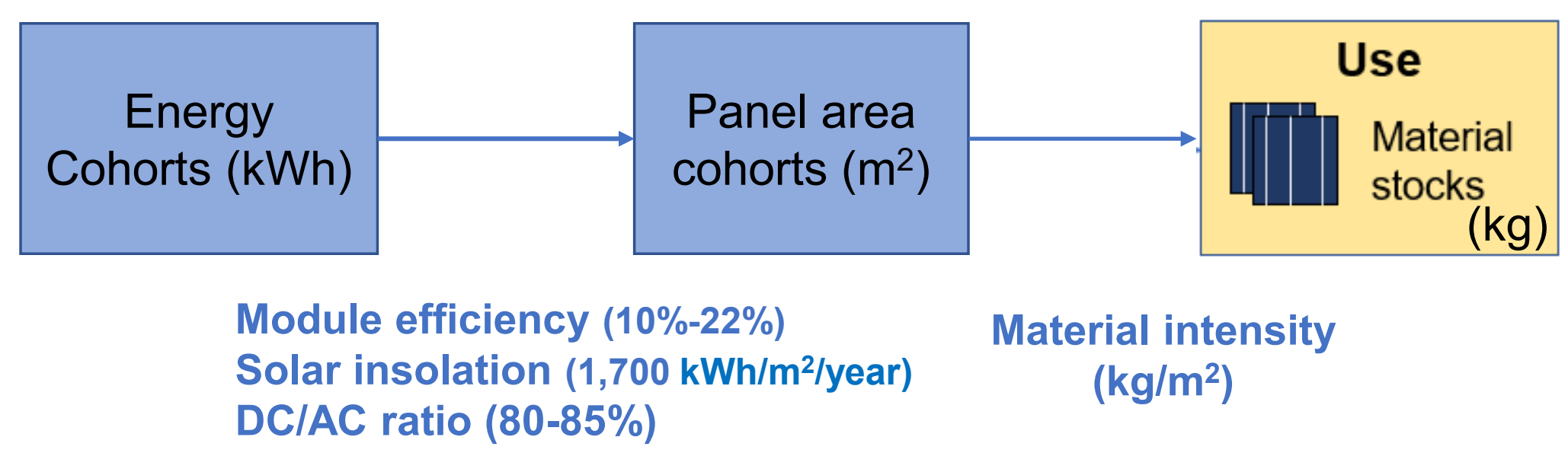

Roadmap reports (e.g., ITRPV, Wood Mackenzie, SEIA) are used to estimate weighted average parameter values with time for each cohort 


\section{Research questions}

Solar glass and aluminum frames are presented as case studies ( $\sim 85 \%$ by $w t . ; \sim 35 \%$ by value)

\section{Baseline Scenario}

What is the size of PV material

flows over time in a baseline scenario?

\section{Impacts of Circularity Practices}

What are the impacts of module reuse, refurbishment, remanufacturing and recycling on waste generation?

\section{Parametric Study}

What are the most influential PV
related parameters in PV module
waste generation?

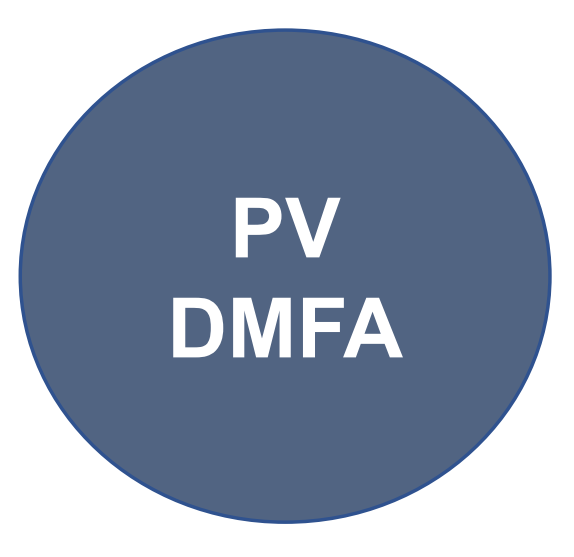

PV module design trends

What are the impacts of module design shifts (i.e., bifacials, high-power large modules) on glass+aluminum?

In a baseline scenario, no panel EOL waste management is assumed 


\section{Soaring Demand for PV Flat Glass}

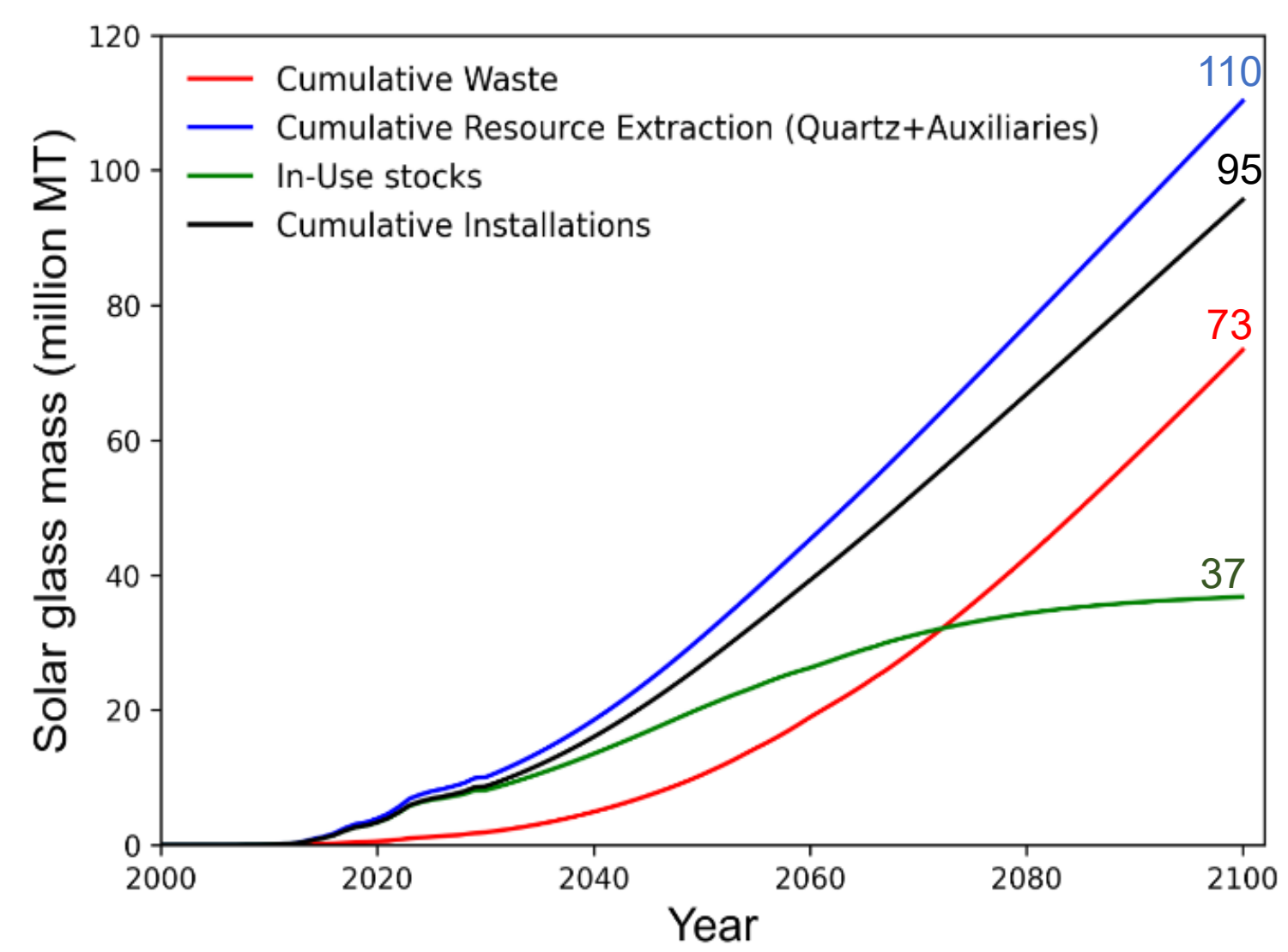

- Over $80 \%$ of life cycle waste arises from use phase $\rightarrow$ EOL circular pathways could reduce this waste stream

- Average worldwide cumulative flat glass manufacturing capacity is $~ 88$ million MT; U.S. share is 12 million MT

- In 2020, flat glass manufacturing deficit doubled glass prices and resulted in interrupted module deliveries 


\section{Growth in PV Aluminum Demand}

PV frames are made of aluminum 6063 alloy (U.S. ISRI code ToTo)

Aluminum 6063 alloys allow for multiple recycling without loss in functionality

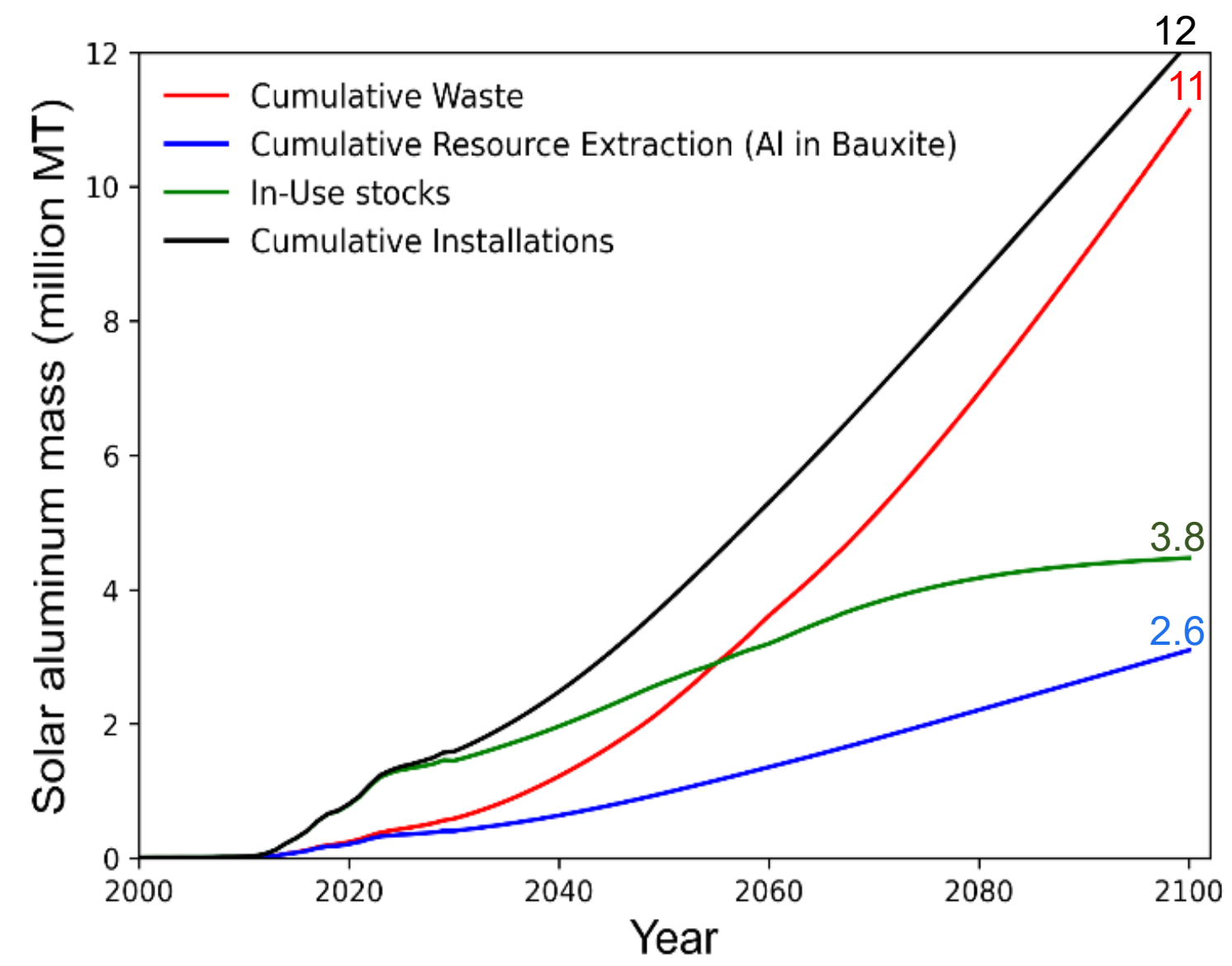




\section{Research questions}

\section{Parametric Study}

What are the most influential PV

related parameters in PV module

waste generation?

Only PV glass is considered for parametric study 


\section{Initial Deployment Parameters Have a Significant Impact on Waste Reduction}

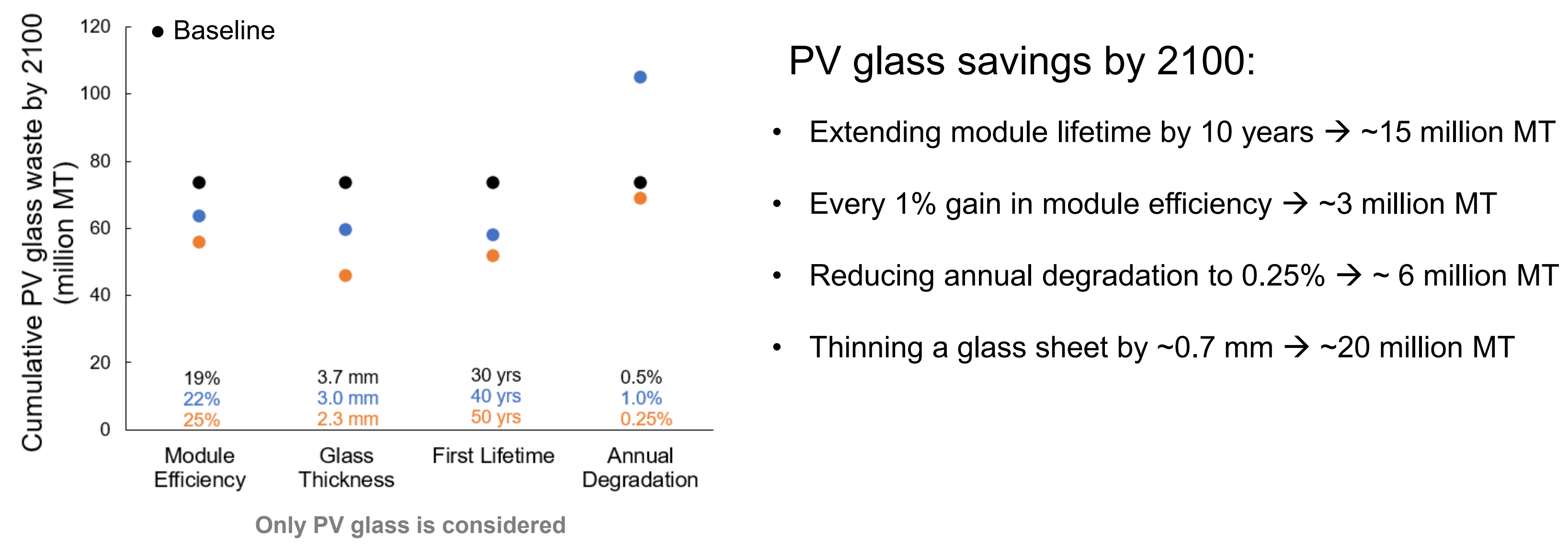




\section{Research questions}

Solar glass and aluminum frames are presented as case studies ( $\sim 85 \%$ wt. ; $\sim 35 \%$ value)

Impacts of Circularity Practices

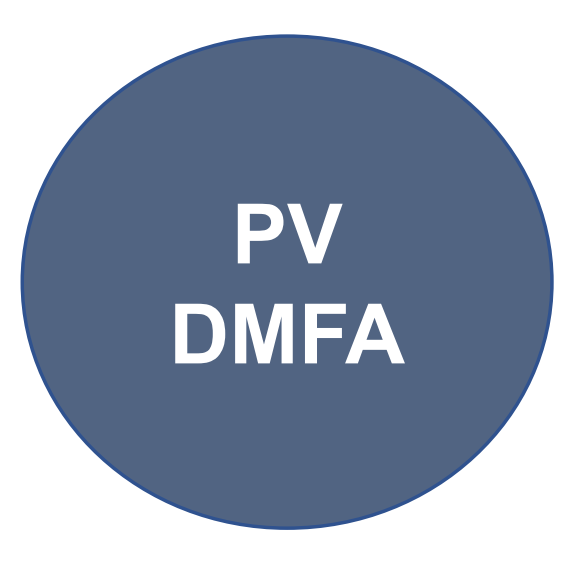

What are the impacts of module reuse, refurbishment, remanufacturing and

recycling on waste generation? 


\section{Dedicated PV Recycling and Component Remanufacturing are Potentially Important Circular Practices}

PV glass savings by 2100 :

- Component extraction for $10 \%$ of modules $\rightarrow 7$ million

ReF/ReC

8

Re-MFG

$\bullet$

$\bullet$

○

Recycle

$\bullet$ MT

- $\quad$ PV recycling $\rightarrow 55$ million MT

Reusing modules, whether refurbished or not, has small effect on waste $\rightarrow$ Fast growth and considerable efficiency degradation in first life

NEDO/FAIS $\rightarrow$ Thermal $\rightarrow$ Unbroken glass Veolia and FRELP $\rightarrow$ Mechanical $\rightarrow$ Broken cullet

- Shredding $\rightarrow$ scrap contamination $\rightarrow$ cannot be accepted by flat glass manufacturers 


\section{Research questions}

Solar glass and aluminum frames are presented as case studies ( $\sim 85 \%$ wt. ; $\sim 35 \%$ value)

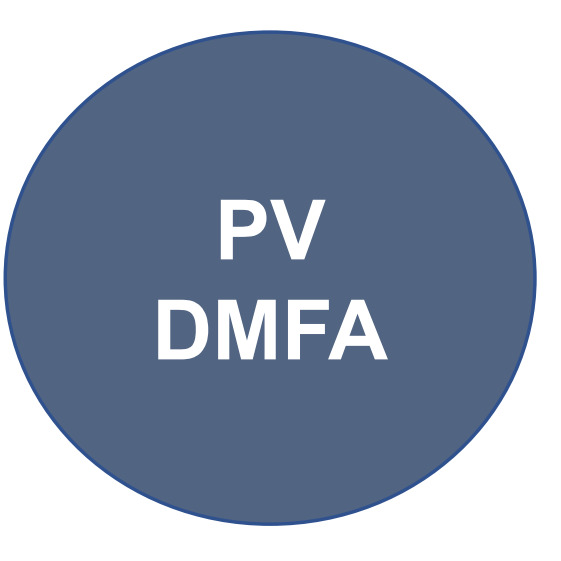

PV module design trends

What are the impacts of module design shifts (i.e., bifacials, high-power large modules) on glass+aluminum? 


\section{Conclusions}

- PV DMFA model estimates PV material flows in their cradle-to-cradle life cycle $\rightarrow$ Can be used as a data support tool for technoeconomic and life cycle analysis sustainability assessments

- High purity, high value dedicated PV recycling and component remanufacturing are potentially important EOL circular practices in the PV circular economy

- Improved system performance and reliability parameters is a key enabler for improved material circularity in PV value chain

PV DMFA model will be released soon as an open-source software tool for users to evaluate materials and scenarios of interest

Acknowledgment:

This conference presentation was developed based upon funding from the Alliance for Sustainable Energy, LLC, Managing and Operating Contractor for the National Renewable Energy Laboratory (NREL) for the U.S. Department of Energy under PRIME CONTRACT NO. DE-AC36-08GO28308 and SUB-2020-10029. All copyrights are protected.

NREL/PR-6A20-80276

Presenter contact:

Sherif A. Khalifarsak335@drexel.edu 